therefore modified Gautier's method and proceeded as follows: The gas from which the carbon dioxide, the illuminants, and oxygen had been removed in the ordinary Hempel scheme of analysis, was passed from a Hempel burette, through a U-tube containing iodine pentoxide heated to $150^{\circ}$ by an oil bath into a Hempel pipette containing a solution of caustic potash. The caustic potash absorbed the carbon dioxide formed by the oxidation of the carbonic oxide so that the contraction in volume after the absorption was complete gave the volume of the latter present. The correction for the vapor tension of iodine was found to be negligible. It does not appear from their article that they ever actually tried their method in an actual analysis of illuminating gas. They did, however, undertake to find out whether or not hydrogen or methane would undergo oxidation on being passed through the iodine pentoxide tube. To this end they made by their method an analysis of a mixture of hydrogen and carbon monoxide, and another analysis of a mixture of methane and carbonic oxide. They report the following results:

\begin{tabular}{lcc} 
& $\begin{array}{c}\text { Found, } \\
\text { cc. }\end{array}$ & \multicolumn{1}{c}{$\begin{array}{c}\text { Mixed, } \\
c c .\end{array}$} \\
Hydrogen $\ldots \ldots \ldots \ldots \ldots \ldots \ldots \ldots \ldots$ & 72.7 & 72.6 \\
Carbon oxide $\ldots \ldots \ldots \ldots \ldots \ldots \ldots \ldots$ & 8.7 & 8.8 \\
Methane $\ldots \ldots \ldots \ldots \ldots \ldots \ldots \ldots \ldots$ & 42.7 & 42.8 \\
Carbon oxide $\ldots \ldots \ldots \ldots \ldots \ldots \ldots$ & 8.1 & 8.0
\end{tabular}

It will be noticed that they give results for two experiments only, and that neither of these properly represents the conditions of practice, as in neither were both hydrogen and methane associated with the carbon monoxide. They do not hesitate, however, to say that their method is very exact and much superior to that in ordinary use.

The method of determination of carbonic oxide by cuprous chloride is so unsatisfactory that it was thought this promised well, and their work was repeated with the following results:

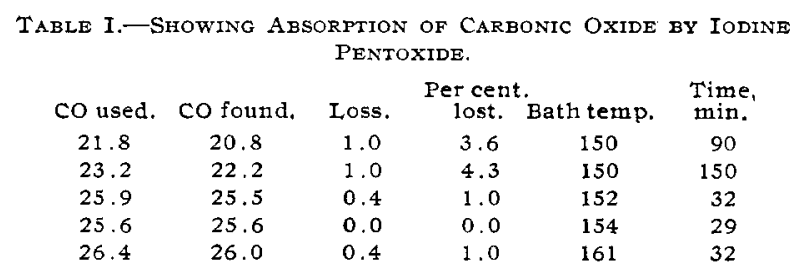

In the last three results the carbonic oxide was mixed with air. It will be noticed that after two and a half hours' passage of the gas through the tube more than 4 per cent. of the gas remained unabsorbed. This would seem to show the impracticability of the method.

To still further test the method a mixture of carbonic oxide, methane, hydrogen and nitrogen was made of about the composition of that left after carbon dioxide, "illuminants" and oxygen had been absorbed from an illuminating gas and passed through the iodine pentoxide. The results are shown in Table II.

\begin{tabular}{|c|c|c|c|c|c|c|c|}
\hline Hydrogen. & $\begin{array}{c}\text { Meth- } \\
\text { aue. }\end{array}$ & $\begin{array}{l}\text { Carb. } \\
\text { oxide } \\
\text { added. }\end{array}$ & $\begin{array}{l}\text { Carb. } \\
\text { oxide } \\
\text { found. }\end{array}$ & Gain. & $\begin{array}{c}\text { Per cent. } \\
\text { gain. }\end{array}$ & $\begin{array}{l}\text { Bath } \\
\text { temp. }\end{array}$ & $\begin{array}{c}\text { T'ime, } \\
\text { minl. }\end{array}$ \\
\hline 24.1 & 44.8 & 25.6 & 28.5 & 2.9 & 11.3 & 157 & 24 \\
\hline 24,4 & 42.3 & 26.4 & 31.3 & 4.9 & 18.6 & 152 & 29 \\
\hline 23.6 & 46.1 & 25.6 & 27.1 & 1.5 & 5.9 & 152 & 28 \\
\hline 26.1 & 46.2 & 24.1 & 27.1 & 3.0 & 12.4 & 152 & 51 \\
\hline 24.6 & 53.5 & 25.7 & 28.1 & 2.4 & 9.3 & 152 & 75 \\
\hline 20.4 & 43.7 & 27.8 & 31.5 & 3.7 & 13.3 & 148 & 30 \\
\hline 24.0 & 46.0 & 26.1 & 26.9 & 0.8 & 3.1 & 150 & 26 \\
\hline
\end{tabular}

It will be noticed from this table that the amount of carbonic oxide found considerably exceeds the amount originally added: The errors of the analysis are not sufficient to account for this and they show no regularity. Moreover, another observer a year previously had obtained almost identical results, the average error found by him being 7.8 per cent., whereas the average error of these results is 9.I. This error, as was shown by two different observers working independently, is not due to the action of the iodine pentoxide upon either the methane or the hydrogen nor the number of times the tube had been used nor the length of time taken by the gas in passing through the tube, but may be due to the breaking up of the iodine pentoxide.

In conclusion it may be said that the method of absorption of considerable quantities of carbonic oxide by iodine pentoxide is inaccurate, irregular in action and tedious and troublesome to use.

Finally our acknowledgments are due to Messrs. J. B. Finnegan and R. W. Lindsay by whom some of the experiments here detailed were performed.

\section{THE COEFFICIENT OF EXPANSION OF GLYCERINE.}

By Arthur M. Comey and Cecil F. Backus. Received October 17, 1909.

Upon examination of the literature on the coefficient of expansion of glycerine, it was found there was some discrepancy between various authorities. Hehner ${ }^{1}$ states that it amounts to 0.00058 for each degree centigrade in the neighborhood of $\mathrm{I} 5.5^{\circ} \mathrm{C}$. It can be calculated from the results of Gerlach's observations ${ }^{2}$ that the value of this factor varies with the temperature according to the following table:

$\begin{array}{cc}\text { Tempera- } & \begin{array}{c}\text { Coefficient } \\ \text { of expansion. }\end{array} \\ 5.0^{\circ} & 0.00057 \\ 12.5^{\circ} & 0.000587 \\ 20.0^{\circ} & 0.00060 \\ 30.0^{\circ} & 0.000619\end{array}$

The necessity of using an accurate coefficient in figuring the results obtained by determining

1 J.S. C. I., 8, 8 (1889).

2 Zeit. anal. Chem.. 24, 111. 
the specific gravity of glycerine at temperatures varying considerably from $x 5.5^{\circ}$ led to the following investigation:

Weights and Balances Used.-The weights and balances used in the following determinations were carefully checked just before beginning the work. The weights that showed slight errors were adjusted so that each was a multiple of the other. The balance beam was found to give accurate weighings when the load and weights were shifted to opposite pans.

Water Bath.-The water, or constant temperature bath, employed to keep the pycnometers at $15.5^{\circ}$, $20^{\circ}, 25^{\circ}$ and $30^{\circ} \mathrm{C}$. for the standardizations and determinations consists of two wooden boxes with an air space of one inch between the sides and bottom. The inner box is twenty inches long, fifteen inches deep and fifteen inches wide, lined with tin, having a shelf Io $\times 8$ inches, eight inches from the bottom. The bath was filled with water so that it covered the shelf to a depth of four and one-half inches. When the pycnometers are set upon the shelf with the water at this depth, the capillaries are entirely submerged, the rubber tubing, described later, serving to protect the contents of the pycnometer. By entirely submerging the body and capillary of the pycnometers, the contents are brought to the same temperature throughout. After the proper temperature was attained, the water was bailed out or drawn off until about one-half inch of the capillary projected out of the water. The temperature of the bath can be regulated by the addition of small pieces of ice, cold water, or hot water to within very narrow limits-less than $0.05^{\circ} \mathrm{C}$.

Several small streams of air served to keep the water agitated, the temperature of the bath being the same at all points at a given time.

Pycnometer.-Geissler specific gravity bottles of $50 \mathrm{cc}$. capacity with centigrade thermometer graduated to $0.2^{\circ}$ ground into neck of bottle, and with side capillary tube with ground glass cap were used in these determinations.

Detailed Description of the Method Employed for the Standardization of Pycnometers. - Freshly boiled, distilled water was rapidly cooled to about i $5^{\circ} \mathrm{C}$. in a flask which was covered with a watch-glass to keep out the air. The capillary of the pycnometer was inserted into a piece of clean and dry rubber tubing $(2.5 \mathrm{~mm}$. in diameter), which was fitted snugly over the capillary and which was $63 \mathrm{~mm}$. in length. The pycnometer was then carefully filled with the air-freed, distilled water by pouring down the side and the thermometer set firmly in place. It was then placed in the water bath and after the pycnometer-thermometer and the standard thermometer reached $15.5^{\circ} \mathrm{C}$., the temperature was kept constant for fifteen minutes more.

The pycnometers were submerged about four and one-half inches in the water bath during the time required for the water in them to attain the desired temperature. The water in the bath was then drawn off until about one-half inch of the capillary projected out of it. The rubber tubing was then removed and the top of the capillary wiped with a dry finger before removing from the water bath. The pycnometer was taken from the bath immediately after the excess water was removed from the top of the capillary and the ground portion of the capillary wiped with a piece of filter paper and the cap placed on tight. The whole pycnometer was then quickly dried by wiping with a dry cloth and weighed as rapidly as possible, without swinging the balance (which is sensitive to $0.2 \mathrm{mg}$. without swinging) to the fourth decimal place. The pycnometers were all standardized at the same time, but each one was weighed before the next was taken out of the water bath, due to the fact that there is a gradual loss of weight if the pycnometers stand for even a few minutes when they contain water. The loss of water is probably due to evaporation through the ground glass joint between the pycnometer and the thermometer.

The water that is forced through the capillary into the rubber tube when the thermometer is set in place is enough to replace any contraction due to lowering of the temperature, provided the difference in temperature is not too great. The rubber tube also allows the capillary to be entirely immersed and yet keeps out the water of the bath.

Standardization of Pycnometer-Thermometers and Pycnometers. - The pycnometer-thermometers were compared with a standard thermometer, which has been checked against several good thermometers at four points, viz.: $15.5^{\circ}, 20^{\circ}, 25^{\circ}$ and $30^{\circ}$, and corrections were applied whenever needed.

The capacities of the pycnometers were determined in duplicate in a water bath at $15.5^{\circ} \mathrm{C}$., while the temperature of the room registered $18^{\circ}$ to $20^{\circ} \mathrm{C}$. The capacities at $15.5^{\circ} \mathrm{C}$. for two of the pycnometers checked results obtained some time previous at room temperatures and figured to grams of water at $15.5^{\circ} \mathrm{C}$. From the weight of water obtained at $t$ degrees the capacity at $\mathrm{I} 5.5^{\circ}$ is obtained from the following formula:

in which,

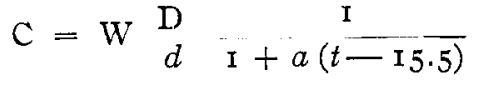

$t=$ Observed temperature.

$\mathrm{W}=$ Capacity in grams of water at $t^{\circ} \mathrm{C}$.

$\mathrm{D}=$ Density of water at $15.5^{\circ} \mathrm{C}$.

$d=$ Density of water at $t^{\circ} \mathrm{C}$. 
$a=$ Coefficient of cubic expansion of glass, which is taken as 0.000025 per $\mathrm{I}^{\circ} \mathrm{C}$. between $\mathrm{I} 5.5^{\circ}$ and $30^{\circ} \mathrm{C}$.

$\mathrm{C}=$ Capacity in grams of water at $15.5^{\circ} \mathrm{C}$.

Table I gives the capacities found and the corrections applied to the thermometers.

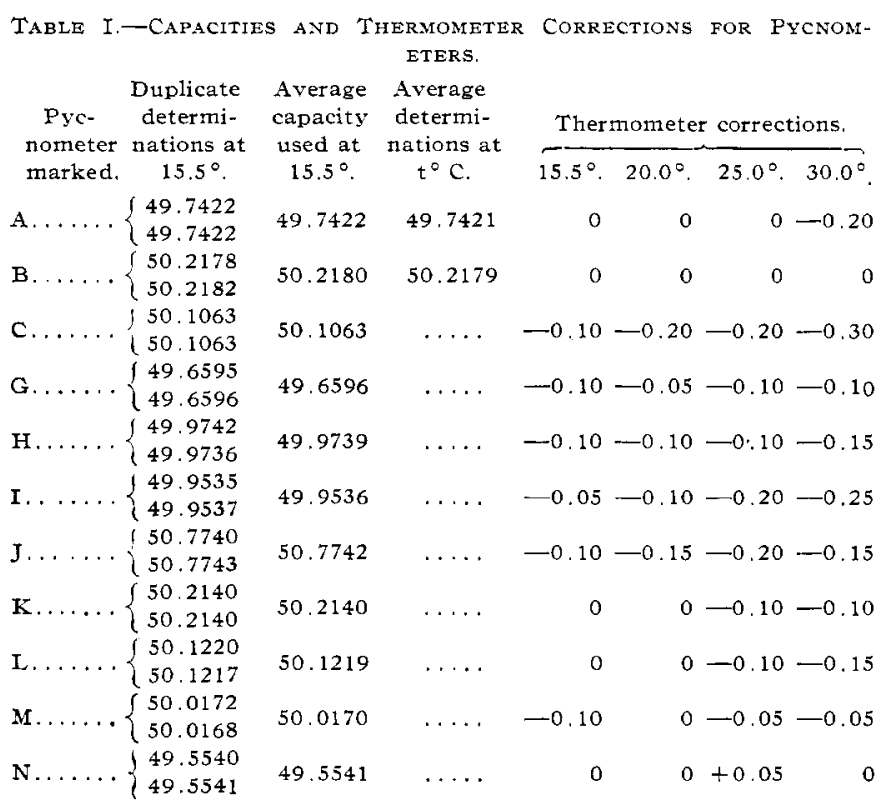

Detailed Description of the Specific Gravity Determinations; Glycerine Used and Method of Transferring it from the Large Sample Bottles to the Pycnometers. - Several samples of dynamite glycerine were used in these determinations, which had been obtained from different manufacturers. These were tested as received and also diluted to cover specific gravities ranging from 1.254 to 1.264 . The glycerine sample in each case was thoroughly shaken at times on three successive days and then allowed to stand four days to free itself of air bubbles before making the determinations. The glycerine was transferred directly from the centre of the large sample bottles to the pycnometers, through a siphon arrangement. With a slight air pressure, the glycerine would flow as rapidly as desired without air bubbles, thus eliminating the danger of any diluted glycerine from the neck of the sample bottle or from the surface of the sample getting in to the pycnometer.

Specific Gravity Determinations.--The pycnometer was first dried with alcohol and ether and then subjected to a current of dry air to remove all traces of ether, weighed and filled by allowing the glycerine to flow from the bottle through the siphon arrangement down the side as rapidly as possible. When filled, the thermometer was inserted into the neck of the pycnometer until the glycerine stood in a globule on top of the capillary. A small quantity of glycerine was then drawn from the large sample into a small, dry beaker and a dry rubber tube $2.5 \mathrm{~mm}$. in diameter and $63 \mathrm{~mm}$. in length, supplied with a glass tube drawn out to a fine capillary, was then filled from it by drawing up some of the glycerine. The rubber tube full of glycerine was then quickly placed on the capillary of the pycnometer and the thermometer set firmly in place. This forced the excess of the glycerine through the capillary into the rubber tube and out through the small capillary. A neater way of manipulating the rubber tube attachment would be to first put it on the pycnometer, fill the pycnometer with glycerine to overflowing and then draw the tube full of glycerine before inserting the thermometer. The pycnometer was then submerged to a depth of $4 \frac{1}{2}$ inches in the water bath, which was kept first at $15.5^{\circ}$, then at $20^{\circ}, 25^{\circ}$ and $30^{\circ} \mathrm{C}$., and allowed to remain for ten or fifteen minutes longer after its thermometer and the standard thermometer in the bath registered the desired temperature. The extra time allowed for the glycerine in the pycnometer to attain a uniform temperature throughout may not have been necessary but was allowed as a precaution.

Just before the pycnometer was ready to be taken from the bath, the water was drawn off until its capillary projected about one-half inch above the water. The rubber tube was then carefully removed, the excess glycerine wiped from the top of the capillary with a dry finger, the pycnometer quickly removed from the bath and the ground portion of its capillary wiped dry with a piece of filter paper and the cap placed on tight. The pycnometer was then wiped first. with a wet and then with a dry cloth until dry and allowed to stand until it had attained the temperature of the room before weighing. Moisture collects very rapidly in damp weather upon the surface of the pycnometer when its temperature is below room temperature. There is no loss in weight upon standing when the pycnometer contains glycerine, as is the case when it contains water, for glycerine is more viscous and less volatile than water. The specific gravity was first determined at $15.5^{\circ} \mathrm{C}$. and successively at $20^{\circ}, 25^{\circ}$, and $30^{\circ} \mathrm{C}$, using the same pycnometer containing the same glycerine for all four determinations, for as the temperature increased the glycerine expanded and was forced out into the rubber tube, which was filled with glycerine each time as described above.

The rubber tube attachment permits the glycerine to be transferred from the sample bottle at room temperature to the pycnometer without first changing its temperature if the specific gravity is to be determined in the water bath at any temperature between $15.5^{\circ}$ and $30^{\circ} \mathrm{C}$. A tube of the size mentioned above with a glass capillary 
will hold enough glycerine to supply the deficiency caused by contraction due to a reduction in temperature of $20^{\circ} \mathrm{C}$. with a liberal excess. It also allows the pycnometer to be submerged to a depth of four and one-half to five inches in the bath whereby all of its contents attain the same temperature throughout, while the capillary admits air and keeps out the water. Even though water were to get in to the rubber tube, the viscosity of the glycerine would not allow it to get into the pycnometer. This was proven by three of the pycnometers being overturned in the water just after
$\mathrm{C}=$ Capacity of pycnometer in grams of water at $\mathrm{I} 5.5^{\circ}$.

$a=$ Thermal coefficient of expansion of glass $=0.000025$ per $\mathrm{I}^{\circ} \mathrm{C}$.

$\mathrm{B}=$ Thermal coefficient of expansion of glycerine.

$t=$ Observed temperature.

Explanation of Tables:

Table $I$ shows the pycnometers used, their capacities and thermometer corrections.

Table II shows the glycerine used, the specific gravity determinations made at $15.5^{\circ} \mathrm{C}$., with the

Table II.-Specific Gravity at $15.5^{\circ}$ and at $20^{\circ}, 25^{\circ}$ and $30^{\circ} \mathrm{C}$

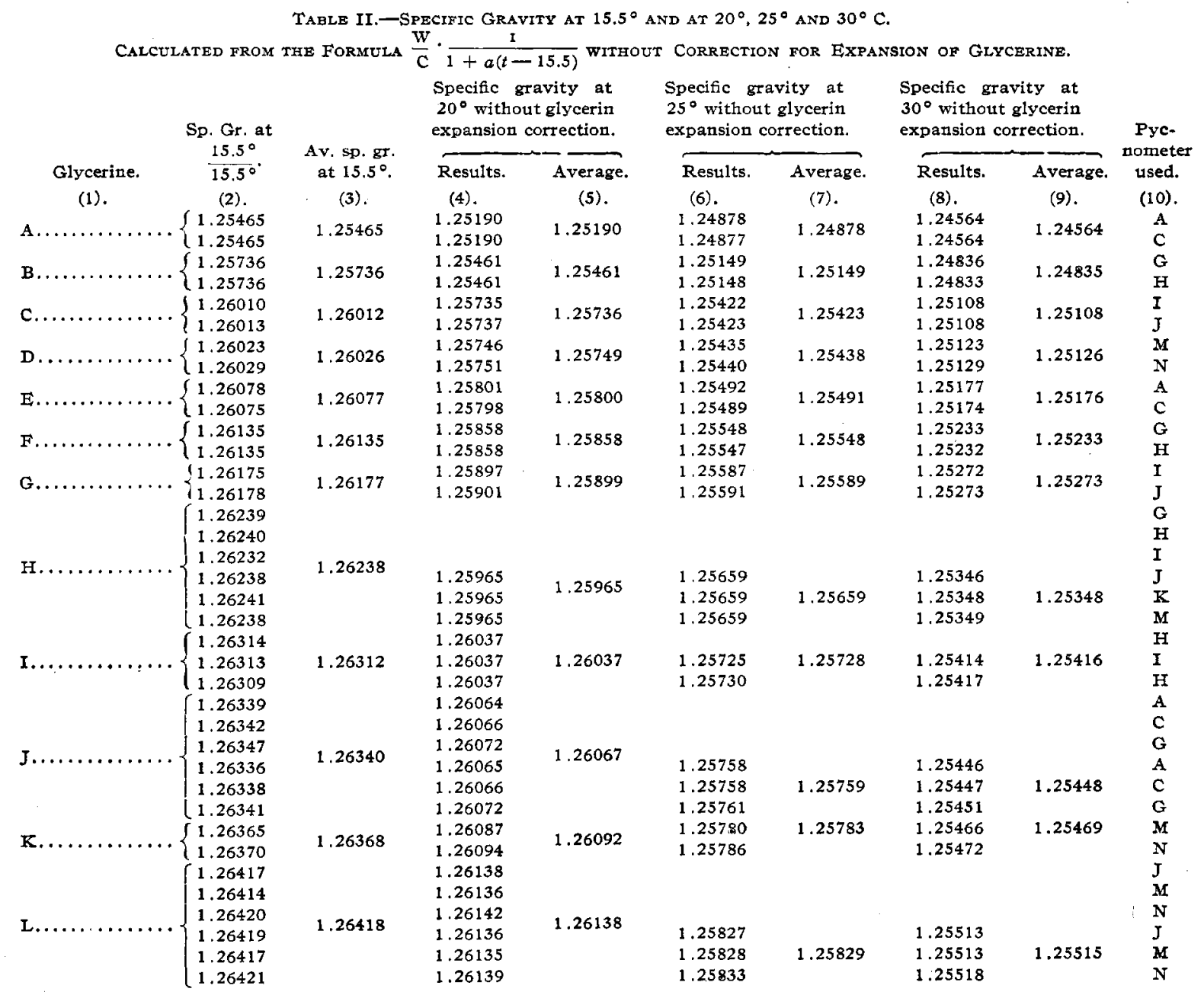

being put into the bath, the determinations being completed and afterward redetermined to make sure that they were correct.

Formula for Calculating the Specific Gravity of Glycerine at $15.5^{\circ} \mathrm{C}$. when Determined at $t$ Degrees Centigrade.-

Specific Gravity at

$$
\frac{15.5^{\circ}}{15.5^{\circ}}=\frac{\mathrm{W}}{\mathrm{C}} \cdot \frac{\mathrm{I}}{\mathrm{I}+a(t-\mathrm{I} 5.5)}+\mathrm{B}(t-\mathrm{I} 5.5)
$$

in which

$\mathrm{W}=$ Weight of glycerine at $t^{\circ}$. average, the specific gravity without the coefficient of expansion correction at $20^{\circ}, 25^{\circ}$ and $30^{\circ} \mathrm{C}$., with the averages and the pycnometer used in each determination.

\section{Table III:}

Column I.-Glycerine used.

Column 2.-Specific gravity at $15.5^{\circ} \mathrm{C}$; Table II, column 5 .

Column 3.-Specific gravity at $20^{\circ} \mathrm{C}$. without glycerine expansion correction; Table II, column 5 .

Column 4.-Difference between specific gravity 
at $15.5^{\circ}$ and $20^{\circ} \mathrm{C}$. without glycerine expansion correction.

Column 5.-Expansion correction per degree at $20^{\circ} \mathrm{C}$. with an average correction at $20^{\circ}$ at the end of the column.
Column I.-Glycerine used.

Column 2.-Specific gravity at $15.5^{\circ} \mathrm{C}$.; Table II, column 3 .

Column 3.-Specific gravity at $20^{\circ} \mathrm{C}$. without. glycerine expansion correction; Table II, column 4 .

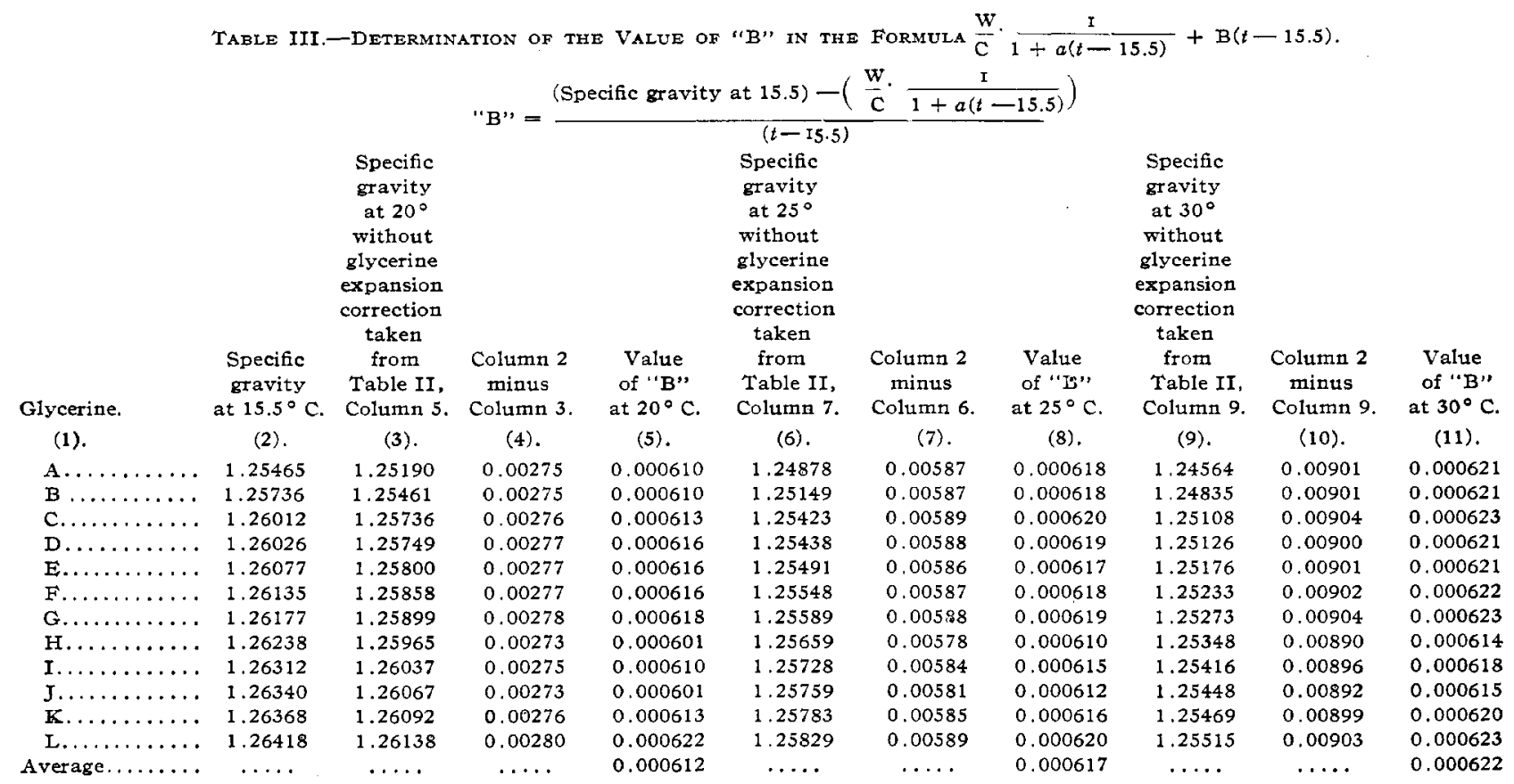

Columns 6, 7 and 8.-Specific gravity at $25^{\circ}$ without glycerine expansion correction and so on as described for columns 3,4 , and 5 with an average correction per degree at $25^{\circ} \mathrm{C}$. at the end of column 8 .
Column 4.-Coefficient of expansion of glycerine taken as $0.0006 \mathrm{I}$ at $20^{\circ} \mathrm{C}$.

Column 5.-Specific gravity determined at $20^{\circ}$ and calculated to specific gravity at $15.5^{\circ}$, using $0.0006 \mathrm{I}$ as the coefficient of expansion at

Table IV.-Specific Gravity of Glycerine Determined at $20^{\circ}, 25^{\circ}$ and $30^{\circ}$ and Calculated to $15.5^{\circ}$ According to the Formula:

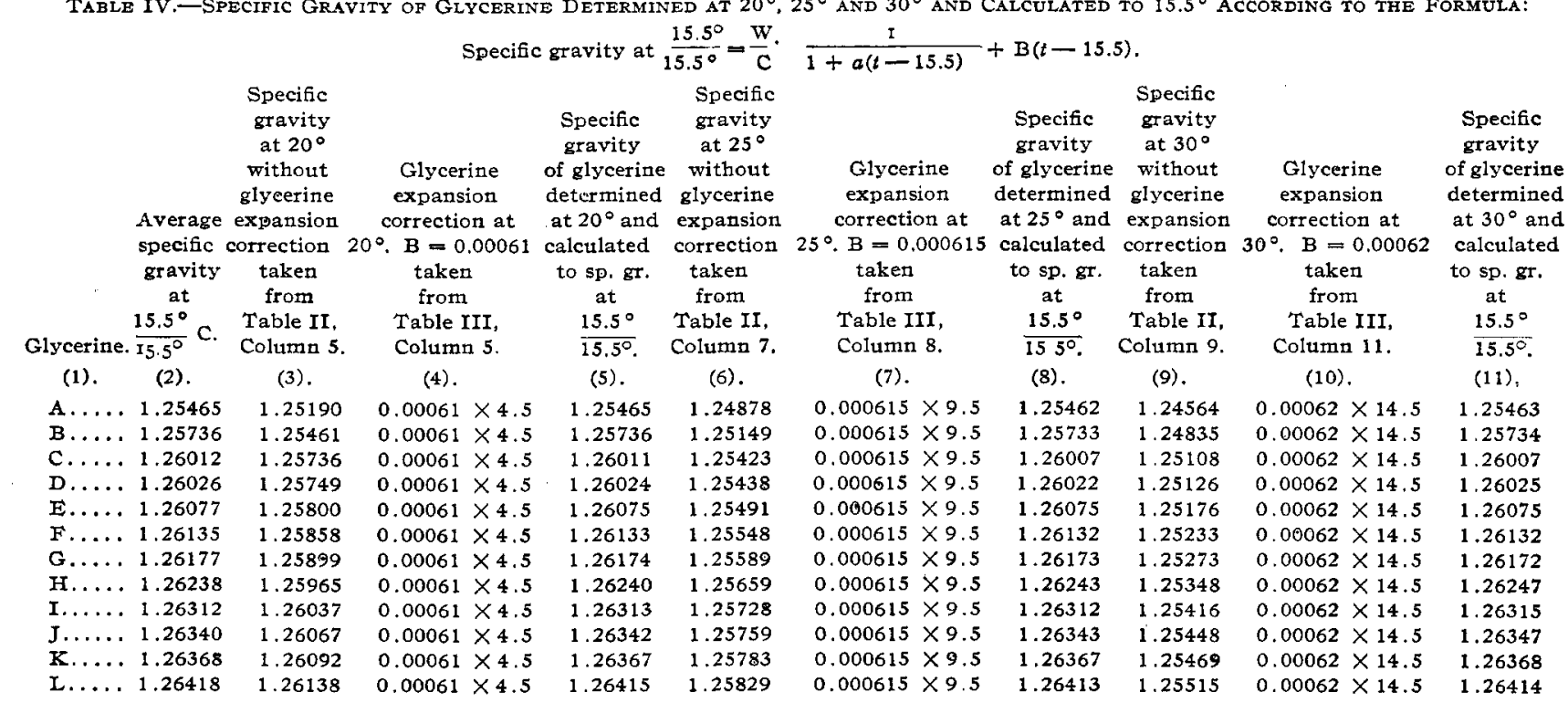

Columns 9, ro and $I T$. - Specific gravity at $30^{\circ} \mathrm{C}$. without glycerine expansion correction and so on as described for columns 3,4 and 5 , with an average correction per degree at $30^{\circ} \mathrm{C}$. at the end of column I $\mathrm{I}$.

Table IV: that temperature for comparison with the specific gravity when determined at $15.5^{\circ} \mathrm{C}$.

Columns 6, 7 and 8.-Specific gravity at $25^{\circ}$ without glycerine expansion correction and so on as described for columns 3,4 and 5 . 
Columns 9, IO and II.-Specific gravity at $30^{\circ}$ C. without glycerine expansion correction and so on as described for columns 3,4 and 5 .

\section{SUMMARY.}

In consideration of the importance connected with obtaining a true value for the thermal coefficient of expansion of glycerine, the greatest care was observed in every detail of the foregoing work. It may appear superfluous to report the determinations of the specific gravity to the fifth decimal place, but as they agreed so closely at that point when different pycnometers were used in doing duplicate determinations, it seemed better to show the actual results obtained, which also shows the degree of accuracy that entered into the work.

From the foregoing results, it is apparent that the published values for the thermal coefficient of expansion of dynamite glycerine are not true between $15.5^{\circ}$ and $30^{\circ} \mathrm{C}$.

Taking the average coefficients of expansion from Table II as $0.0006 \mathrm{I} 2$ at $20^{\circ} \mathrm{C}$, $0.0006 \mathrm{I} 7$ at $25^{\circ} \mathrm{C}$. and 0.000622 at $30^{\circ} \mathrm{C}$, which are in round numbers $0.0006 \mathrm{I}$ at $20^{\circ}, 0.0006 \mathrm{I} 5$ at $25^{\circ}$ and 0.00062 at $30^{\circ}$, and applying them as shown in Table IV, the determinations show very close agreement with the determinations made at $15.5^{\circ} \mathrm{C}$.

The idea in using the round numbers $0.0006 \mathrm{I}$, 0.0006 I 5 and 0.00062 as the coefficients of expansion for glycerine is that they are easily remembered and are accurate enough for all practical purposes.

EASTERN LABORATORY,

E. I. DUPont deNemours Powder Co. September 1, 1909 .

\section{FLASH, FIRE AND EXPLOSION TESTS ON MIX- TURES OF CARBON TETRACHLORIDE AND NAPHTHA.}

By EDW. A. BARRIER.

Received September 2, 1909

The frequent occurrence of fires, explosions, or both, resulting from the wide-spread use of naphtha in removing oil from textile materials or metal goods in factories, makes it a matter of serious concern that no suitable, non-inflammable substitute has as yet been found. Of late years carbon tetrachloride has received some attention in this connection, but its comparatively high cost has barred its use except in a very limited way. Recent reductions in the price of this material, however, and the fact that a certain percentage of naphtha can be added without rendering the mixture inflammable have brought the cost of such a mixed solvent down to a point where it can be used in many cases, especially, if the spent solvent is reclaimed by distillation.

The importance of this matter led to the follow- ing series of experiments which were undertaken with the object of determining how great a percentage of naphtha, of various gravities, could be added to carbon tetrachloride, and still leave the mixture free from fire and explosion hazard.

Four samples of commercial naphtha, labeled as below, were obtained from a petroleum refiner for the tests. The specific gravities of these samples were found to be as follows:

\begin{tabular}{|c|c|c|}
\hline & $\begin{array}{l}\text { Labeled. } \\
54^{\circ} \text { Bé. }\end{array}$ & $\begin{array}{c}\text { Sp. gr. found. } \\
0.7556-551^{\circ} \mathrm{Bé}\end{array}$ \\
\hline$\ldots \ldots \ldots \ldots$ & $62^{\circ} \mathrm{Bé}$ & $0.7251-63^{\circ}$ Bé. \\
\hline $\begin{array}{l}\text { III. } \ldots \ldots \ldots \ldots \ldots \\
\text { IV } \ldots \ldots \ldots \ldots\end{array}$ & Motor gasoline, $68-72^{\circ}$ Bé. & $0.6982-7012^{\circ}$ Bé. \\
\hline
\end{tabular}

Distillation tests of these naphthas were made with the following results:

\begin{tabular}{|c|c|c|c|c|c|}
\hline Gravity. & $80-100^{\circ}$ & $100-110^{\circ}$ & $110-120^{\circ}$ & $120-130^{\circ}$ & $130-140^{\circ}$. \\
\hline $551 / 4^{\circ}$ & & & & $17.0 \mathrm{cc} .^{1}$ & $20.5 \mathrm{cc}$. \\
\hline $63^{\circ}$ & $12.5 \mathrm{cc}^{2}$ & $23.5 \mathrm{cc}$ & $22.0 \mathrm{cc}$ & $18.0 \mathrm{cc}$ & $8.0 \mathrm{cc}$ \\
\hline Gravity. & $140-150^{\circ}$. & $150-160^{\circ}$ & $160-170^{\circ}$ & $170-180^{\circ}$. & Above $180^{\circ}$ \\
\hline $\begin{array}{l}55^{1} / 4^{\circ} \\
63^{\circ}\end{array}$ & $\begin{array}{l}17.0 \mathrm{cc} \\
16.0 \mathrm{cc} \text {. above }\end{array}$ & $\begin{array}{l}11.0 \mathrm{cc} \\
\mathrm{e} 140^{\circ}\end{array}$ & $9.5 \mathrm{cc}$. & $7.0 \mathrm{cc}$ & $17.0 \mathrm{cc}$ \\
\hline Gravity. & $50-60^{\circ}$. & & $70^{\circ}$ & $70.80^{\circ}$ & $80-90^{\circ}$ \\
\hline $\begin{array}{l}701 / 2^{\circ} \\
751 / 2^{\circ}\end{array}$ & $\begin{array}{l}2.0 \mathrm{cc} .3 \\
3.5 \mathrm{cc} .\end{array}$ & & $\begin{array}{l}\text { ce. } \\
\text { cc. }\end{array}$ & $\begin{array}{l}19.0 \mathrm{cc} \\
24.0 \mathrm{cc} .\end{array}$ & $\begin{array}{l}24.5 \mathrm{cc} . \\
18.0 \mathrm{cc} .\end{array}$ \\
\hline Gravity. & $90-100^{\circ}$. & 100 & $10^{\circ}$. & $110-115^{\circ}$. & Above $115^{\circ}$. \\
\hline $\begin{array}{l}70^{1 / 2^{\circ}} \\
75^{1 / 2} 2^{\circ}\end{array}$ & $\begin{array}{l}21.0 \mathrm{cc} . \\
13.0 \mathrm{cc} .\end{array}$ & $\begin{array}{r}11 \\
5\end{array}$ & $\begin{array}{l}\text { cc. } \\
\text { cc. }\end{array}$ & $\begin{array}{l}4.0 \mathrm{cc} \\
12.0 \mathrm{cc} \text { abo }\end{array}$ & $\begin{array}{l}14.0 \mathrm{cc} . \\
\text { ve } 110^{\circ}\end{array}$ \\
\hline & FIASH & $A N D F$ & POINT & TESTS. & \\
\hline
\end{tabular}

The flash and fire point tests were made in the open cup of the New York State Board of Health tester, and also in some cases, in a six-inch evaporating dish. No difficulty was experienced in determining the flash points of the various mixtures, but in no case could a definite fire point be found. On raising the temperature from the flash point, the liquid would usually flash and burn for one or two seconds, and then go out of itself. A further raising of the temperature resulted in some cases in lengthening the time of burning, and, in other cases, in decreasing the time of burning. Repeated tests of the same mixture, however, gave reasonably concordant results.

The mixtures containing the limiting amounts of naphtha, which are later stated to be reasonably safe, were tested in an evaporating dish, in addition to the open cup, as it was thought that this form of container with a large evaporating area was more comparable to the ordinary open bath frequently found in works.

On account of the absence of a true fire point the temperature was gradually raised from the flash point to the boiling point, and the observations recorded below were taken.

The results are given in the following table:

\footnotetext{
1 Distillation began at $123^{\circ}$

2 Distillation began at $85^{\circ}$.

3 Distillation began at $55^{\circ}$.
} 